\title{
Gonadal dysgenesis in rainbow trout Salmo gairdneri
}

\author{
Roger Lee Herman ${ }^{1}$ \& Harold L. Kincaid ${ }^{2}$ \\ 'U.S. Fish and Wildlife Service, National Fish Health Research Laboratory, Box 700, Kearneysville, West Virginia 25430, USA \\ ${ }^{2}$ U.S. Fish and Wildlife Service, National Fishery Research and Development Laboratory, R. D. \# 4, Box 63, Wellsboro, Pennsylvania 16901, USA
}

ABSTRACT: A family of infertile rainbow trout Salmo gairdneri was produced by mating a single male and female from a 3-generation inbred line. No germinal cells were evident histologically in the gonads. Steroid levels were indicative of sexually inactive fish. Chromosomes appeared normal

A family of rainbow trout Salmo gairdneri, produced by mating a single male and female from an inbred population at Fish Lake (Utah, USA) in January 1980, failed to produce the expected numbers of sexually mature fish at 2 yr of age. Of 66 fish in the lot, only 3 (2 females, 1 male) became ripe.

Histological examination was undertaken in an effort to identify the cause of immaturity.

In April 1983, gross examination showed that fish with the external configuration of females were robust and had heavy visceral fat deposits; internal organs appeared to be normal, except for the gonad. The gonad was evident as a strip of fluid-filled, clear tissue 1 to $2 \mathrm{~mm}$ wide, extending along the full length of the body cavity. One fish showing the external characteristics of a male discharged copious thin, clear fluid when handled. Dissection revealed little visceral fat and a gonad of the size and shape expected; like the gonads of the females, however, it was filled with a thin, clear fluid. The rest of the internal organs appeared normal.

An additional apparent male and 3 apparent females were examined in March 1984. Gross appearance was similar to that of fish examined in 1983, except that the male also had heavy visceral fat deposits.

In July 1984, the remaining 19 fish (2 apparent males, 17 apparent females) were sacrificed. Again, visceral fat was very heavy. Gonads of apparent females showed little development, being only 1 to $3 \mathrm{~mm}$ wide. Two fish had gray-to-white lumps suggestive of localized sperm production. No fluid was evident. The 2 apparent males had larger gonads - up to $1.5 \mathrm{~cm}$ wide - with cream-to-white nodules, but no obvious fluid.
Histological examination revealed a similar pattern in gonads of both apparent females and apparent males. The gonads of fish sampled in April 1983 and March 1984 consisted of a well-vascularized connective tissue framework with a layer of lobule boundary (Sertoli) cells that in the apparent female appeared multilayered in some areas. There was no evidence of germinal cell development.

The histological picture of gonads sampled in July 1984 was of generally solid cords of lobule boundary cells in which tubule lumina were difficult to discern. Cystic areas were present but lacked any particular pattern.

Steroid levels were determined by radio-immunoassay from blood samples taken in December 1983 from 37 fish in the sterile lot and from fish of 2 nonsterile lots - 1 normally spawning in January (12 fish) and 1 in October (11 fish). Mean estradiol level in the sterile lot was low $\left(0.20 \mathrm{ng} \mathrm{m} \mathrm{m}^{-1}\right)$, corresponding to levels in females $\left(0.19 \mathrm{ng} \mathrm{m}^{-1}\right)$ of the fall spawning strains that were 2 to 3 mo past spawning and in active males $\left(0.19 \mathrm{ng} \mathrm{ml}^{-1}\right)$ of the winter spawning strains.

Mean testosterone level of $3.90 \mathrm{ng} \mathrm{ml}^{-1}$ in the sterile fish was much lower than the means for the sexually inactive fall spawning strain males.

Chromosome analysis indicated an apparent normal diploid complement.

Sex differentiation of rainbow trout occurs very early in the development of the individual. Takashima et al. (1980) were able to distinguish ovaries in fish $67 \mathrm{~d}$ postfertilization, and spermatogonia by $100 \mathrm{~d}$. Tissue samples examined in our study showed no evidence of any type of germinal cell development. Although female types dominated the population, some individuals showed morphological secondary male sex characteristics, and growth rates were normal; consequently we speculate that the condition was not the result of an XO condition of sex chromosomes. As the 
chromosome analysis showed a diploid number, failure to mature cannot be attributed to a haploid or triploid condition. Most likely the primordial germ cells failed to form or they failed to migrate into the gonadal region. A similar dysgenesis caused by autosomal recessives is known in cattle, rabbits, and pigs (Jones \& Hunt 1983). In humans, del Castillo's syndrome is similar, and is considered a germ cell migration failure; however, specific cause is unknown (del Castillo et al. 1947).

The use of sterile fish for food production has been proposed as one method of increasing fish production efficiency by elimination of precocious males and of the reduced growth rates associated with the onset of sexual maturity. A genetically produced sterile line such as the one reported here would be preferred over a hormonally induced population for food production.

One of the theoretical advantages claimed for the production of sterile fish is that energy normally directed to developing sex products would be directed into edible tissues. This assumed advantage did not appear to occur in our sterile line. The heavy masses of visceral fat that filled the body cavity of most of the fish examined suggests that excess energy was stored as fat, although the abdominal walls of most of the fish were thicker and the fish were deeper bodied than those in companion nonsterile lots. Feeding rates, which were probably too high, presumably produced the additional fat deposits.

Although the development of this sterile line was accidental, it showed the feasibility of developing such lines intentionally, and indicates that a change in feed composition or feeding rate would be necessary to achieve the theoretical feed conversion advantage of such a fish.

\section{LITERATURE CITED}

Del Castillo, E. B., Trabucco, A., de la Balze, F. A. (1947). Syndrome produced by absence of the germinal epithelium without impairment of the Sertoli or Leydig cells. J. Clin. Endocrinol. \& Metab. 7: 493-509

Jones, T. C., Hunt, R. D. (1983). Veterinary pathology. 5th edn. Lea and Febiger, Philadelphia

Takashima, F., Patino, R., Nomura, M. (1980). Histological studies on the sex differentiation in rainbow trout. Bull. Jap. Soc. scient. Fish. 46: 1317-1322

Responsible Subject Editor: Dr. G. Peters; accepted for printing on September 2, 1986 